

\section{Sumário}

I. Crônicas do Direito Internacional ................................................1

MAPEAMENTO E COMPARAÇÃO DE ACORDOS DE PROTEÇÃO DE INVESTIMENTOS INTERNACIONAIS na América Latina e Central 1990 a 2018 .............................................................. 3

Anderson Fonseca Machado (organizador), Letícia Braga Carvalho Kataoka (organizadora), Ana Terra Teles de Meneses, André Leão, Andrea Luísa de Oliveira, Edilson Enedino das Chagas, Henrique Haruki Arake Cavalcante, Mariana Rezende Maranhão da Costa, Rafael Freitas Machado, Vitor Levi, Wilson Sampaio Sahade Filho

Private International Law Chronicles ....................................................................19

Nadia de Araujo, Marcelo De Nardi, Inez Lopes e Fabrício Polido (org.)

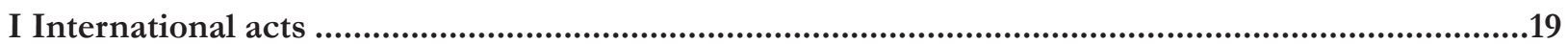

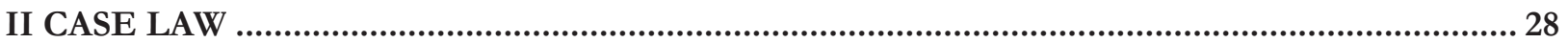

II. Dossiê Especial: Arbitragem e Direito Internacional ..........................35

EL ROL DE LAS INSTITUCIONES ARBITRALES EN EL DESARROLLO DEL ARBITRAJE INTERNACIONAL..... 37 Ivette Esis

REVISITANDO A AVERSÃo BRASILEIRA À CLÁUSULA INVESTIDOR-EsTADO: CAPITALISMO DE EsTADO

E TREATY-SHOPPING

Marcelo Simões dos Reis e Gustavo Ferreira Ribeiro

Arbitral interpretation OF INVESTMENT TREATIES: PROBLEMS AND REMEDIES FOR THE DEBATE ON "LEGITIMACY"

Santiago Díaz-Cediel

Arbitragem Internacional sob Anexo VII da Convenção das Nações Unidas sobre o Direito do Mar e as Controvérsias Mistas: Análise de Casos Recentes

Alexandre Pereira da Silva

Arbitragem de investimentos e o meio ambiente: reflexões sobre o caso Ethyl CorpoRATION V. CANADÁ.

Patrícia Maria da Silva Gomes 
Homologação de SENTENÇA ARBitral ESTRANGEIRA ANULADA NA ORIGEM: o CASo EDF IN-

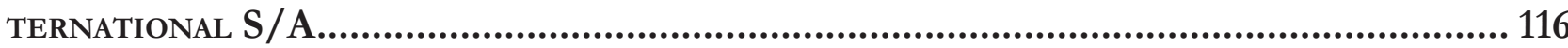

Patrícia Maria da Silva Gomes

II. Artigos sobre outros temas 129

International Constitutional Court: Rise and Fall of an International Debate 131 Arthur Roberto Capella Giannattasio, Taina Ometto Bezerra, Elizabeth Bannwart, Débora Drezza, Jessica Buchler, Giovanna Martins e Breno Oliveira

International Constitutional Court: Rise and Fall of an International Debate 148 Janaína Gomes Garcia de Moraes e Patricio Alvarado

InVestigação histórica do Conteúdo da Concepção de Trabalho Decente no ÂMbito DA OIT E UMA ANÁLISE DE SUA JUSTICIABILIDADE 166 Silvio Beltramelli Neto e Julia de Carvalho Voltani

O DIÁLOGO ENTRE FONTES NORMATIVAS E O CONTROLE DE CONVENCIONALIDADE: ENTRE O LIVRE COMÉRCIO E O DESENVOLVIMENTO ECONÔMICO E SUSTENTÁVEL 187

Eduardo Biacchi Gomes e Julia Colle Marinozzi

O DIREITO INTERNACIONAL DO DESENVOLVIMENTO E SUAS RAÍZES IMPERIALISTAS NO CONTEXTO DO PLURALISMO NORMATIVO: POR UM PARADIGMA LIBERTÁRIO E NÃO (NEO)LIBERAL 201

Lucas Silva de Souza e Jânia Maria Lopes Saldanha

ENTRE O ESCUDO E A ESPADA: CARACTERIZANDO O LAND GRABBING COMO CRIME CONTRA A HUMANIDADE

Rodolfo Soares Ribeiro Lopes

Descolonialismo e o Direito Internacional Privado na América Latina: desvendando NOVOS PARADIGMAS

Eduardo Biacchi Gomes e Luis Alexandre Carta Winter

Criminalização de imigrantes ILEgais Na União Europeia: novos PaRAdigmas COM base nO CASO CELAJ 253

Felipe Augusto Lopes Carvalho 
O CASO INTEL: O IMPACTO NA EVOLUÇÃO DA TEORIA DOS EFEITOS NO DIREITO DA CONCORRÊNCIA DA UNIÃo EUROPEIA...............................................................................270

Augusto Jaeger Junior e Mariana Sebalhos Jorge

The DUTY OF CARE OF PARENT COMPANIES: A TOOL FOR ESTABLISHING A TRANSNATIONAL ENVIRONMENTAL CIVIL LIABILITY

Mathilde Hautereau Boutonnet 


\title{
Mapeamento e comparação de acordos de proteção de investimentos internacionais na América Latina e Central 1990 a 2018
}

\author{
Anderson Fonseca Machado (organizador); \\ Letícia Braga Carvalho Kataoka (organizadora); \\ Ana Terra Teles de Meneses; André Leão; Andrea Luísa de Oliveira; \\ Edilson Enedino das Chagas; Henrique Haruki Arake Cavalcante; \\ Mariana Rezende Maranhão da Costa; Rafael Freitas Machado; \\ Vitor Levi; Wilson Sampaio Sahade Filho*
}

\section{Introdução}

A proteção jurídica dos investimentos estrangeiro é regulada pelo Direito Internacional dos Investimentos, subárea do Direito Internacional Público. Em face da inexistência de um normativo único ou consolidador, o Direito Internacional dos Investimentos estabeleceu-se primeiro em bases consuetudinárias, emergindo por meio de costumes e decisões adotadas em soluções de conflitos que envolvam investimentos internacionais, evoluindo até o surgimento de tratados internacionais de proteção aos investimentos estrangeiros.

Estes acordos internacionais, considerados como gênero, são internacionalmente conhecidos como IIA (International Investment Agreement) e podem ser divididos em dois grandes grupos ou espécies. Por um lado, existem os tratados bilaterais, amplamente conhecidos como BIT (Bilateral Investment Treaty); e tratados multilaterais com provisões acerca de proteção aos investimentos estrangeiros, aqui denominados TIP (Treaty with Investment Provision).

Apesar dos inúmeros esforços realizados para o surgimento de um quadro regulatório internacional abrangendo a proteção dos investimentos estrangeiros, a ausência de entendimento entre países importadores e exportadores de capitais, resultou como solução, a adoção dos BITs, que cresceram de forma exponencial desde a década de 1900 até somar atualmente mais de 3.000 tratados $^{1}$.

O primeiro BIT foi pactuado entre Alemanha e Paquistão em 1959. Progressivamente, surgiram diversos instrumentos similares - fato justificado em razão da maior facilidade na obtenção de acordo entre dois Estados do que entre uma pluralidade de Estados com interesses antagônicos. Ademais, do ponto de vista dos Estados desenvolvidos, mostra-se mais viável a celebração de acordos bilaterais - nos quais os Estados menos desenvolvidos têm pouco poder de barganha - do que a assunção de compromissos multilaterais, em que os Estados menos desenvolvidos têm a possibilidade de unir-se para reivindicar a contemplação de seus interesses ${ }^{2}$.

$\mathrm{Na}$ doutrina e na jurisprudência, há certo consenso de que existem pon-

* Os autores são doutorandos do Programa de Doutorado do Centro Universitário de Brasília-UniCEUB.

E-mail: anderson.fonseca.machado@gmail.com
Fonte: Ministério da Indústria, Comércio Exterior e Serviços (MDIC). https://www. mdic.gov.br/comercio-exterior/negociacoes-internacionais/218-negociacoes-internacionais-de-investimentos/1949-nii-acfi

FERNANDES, Érica Capella. FIORATI, Jete Jane. Os ACFIs e os BITs assinados pelo Brasil. RIL Brasília a. 52 n. 208 out./dez. 2015 p. 247-276 
tos comuns em discussões envolvendo os direitos dos investimentos, tais como: o critério para identificar um investimentos; a questão da nacionalidade do investidor; o tratamento justo e equitativo; a proteção e segurança plenas dos investimentos internacionais; a desapropriação no contexto do poder regulatório do Estado; a proteção contra a discriminação (claúsula da nação mais favorecida e tratamento nacional); e os deveres sociais dos investidores internacionais.

Considerando esse processo evolutivo e ainda a carência de harmonização em soluções envolvendo temas semelhantes, buscou-se mapear e comparar os textos de acordos de proteção dos investimentos celebrados por países da América Latina, do ponto de vista do investidor e do Estado, a fim de verificar a existência de alguma uniformização acerca do assunto dentre os países da América Latina, bem como .

O trabalho de mapeamento, visando analisar os tratados de , adotou como critério de seleção ou delimitação tratados assinados pelos países latino-americanos na década de 1990 e compará-los aos celebrados mais recentemente. Os dados foram obtidos e selecionados por meio do acesso ao sítio eletrônico http://investmentpolicyhub.unctad.org/IIA, sendo escolhidos 36 IIAs.

\section{Paramêtros metodológicos de comparação}

A fim de orientar as comparações entre os tratados mapeados, utilizou-se como parâmetros selecionados como mecanismos de cotejamento, a existência dos seguintes conteúdos nos IIAs:

a) Tratamento justo e equitativo (TJE): análise sobre o nível de abertura;

b) Proteção e segurança dos investimentos (PSI): nível de abrangência de proteção contemplado;

c) Cláusula guarda-chuva (CGC): possibilidade de proteção por BIT face a eventual violação de contrato de investimentos;

d) Normatização sobre desapropriação, direta e indireta (DES): especificidade de situações normatizadas; e) Clausula da nação mais favorecida (NMF): exame de previsão e análise sobre nível de contemplação.

f) Cláusula de responsabilidade Social (CRS): análise de nível da responsabilidade prevista;

Conforme a metodologia utilizada, os IIAs selecionados para mapeamento foram então divididos em 9 (nove) grupos de análise:

- IIAs cujo Brasil figura como parte;

- IIAs cuja Colômbia figura como parte;

- IIAs em que o Chile figura como parte;

- IIAs em que Comunidade Andina figura como parte;

- IIAs em que Uruguai figura como parte;

- IIA em que Venezuela figura como parte;

- Outros IIAs firmados por países latinoamericanos;

- IIAs firmados por países da América Central;

- Acordos firmados pelo Mercosul.

\section{Os acordos internacionais de proteção de investimentos estrangeiros celebrados por países latinoamericanos}

\subsection{IIAs cujo Brasil figura como parte}

\section{BIT Angola - Brasil (2015)}

a) Critério "a” (TJE) - Não há previsão de cláusula de tratamento justo e equitativo.

b) Critério "b" (PSI) - Não há previsão de cláusula de proteção e segurança dos investimentos.

c) Critério "c" (CGC) - Sim, há garantia de proteção por BIT em caso de descumprimento de contrato de investimentos.

d) Critério "d" (DES) - Não há explicitação de casos de desapropriação indireta. Contudo, estipula-se com- 
pensação justa em caso de "expropriação" (nacionalização).

e) Critério "e" (NMF) - Há previsão, contempla isonomia em relação a tratamentos pré e pós-estabelecimento.

f) Critério "f" (CRS) - Há previsão genérica. Exige maior comprometimento possível dos investidores.

\section{BIT Chile - Brasil (1994)}

a) Critério "a" (TJE) - Há previsão de cláusula de tratamento justo e equitativo. Abordagem genérica.

b) Critério "b" (PSI) - Há previsão de cláusula de proteção e segurança dos investimentos. Abordagem genérica.

c) Critério "c" (CGC) - Não há garantia de proteção por BIT em caso de descumprimento de contrato de investimentos.

d) Critério “d” (DES) - Não há explicitação de casos de desapropriação indireta. Contudo, estipula-se compensação justa em caso de "expropriação" (nacionalização).

e) Critério “e” (NMF) - Há previsão, contempla isonomia em relação a tratamentos pós-estabelecimento.

f) Critério "f” (CRS) - Não há previsão genérica.

\section{BIT Chile - Brasil (2015)}

a) Critério “a” (TJE) - Não há previsão de cláusula de tratamento justo e equitativo.

b) Critério "b" (PSI) - Não há previsão e cláusula de proteção e segurança dos investimentos.

c) Critério "c" (CGC) - Não há garantia de proteção por BIT em caso de descumprimento de contrato de investimentos.

d) Critério "d" (DES) - Há previsão de desapropriação e sua respectiva compensação. Não há explicitação de casos de desapropriação indireta.

e) Critério "e" (NMF) - Contempla isonomia em relação a tratamentos pós-estabelecimento.

f) Critério "f" (CRS) - Há previsão detalhada. Exige maior comprometimento possível dos investidores. Obedecer as "Linhas Diretrizes para Empresas Multi- nacionais" da Organização para a Cooperação e o Desenvolvimento Econômico".

\section{BIT França - Brasil (1995)}

a) Critério “a” (TJE) - Há previsão de cláusula de tratamento justo e equitativo. Abrangência detalhada.

b) Critério "b" (PSI) - Há previsão e cláusula de proteção e segurança dos investimentos.

c) Critério "c" (CGC) - Não há garantia de proteção por BIT em caso de descumprimento de contrato de investimentos.

d) Critério "d" (DES) - Há previsão de desapropriação direta e indireta e sua respectiva compensação.

e) Critério "e" (NMF) - Contempla isonomia em relação a tratamentos pós-estabelecimento.

f) Critério "f”" (CRS) - Não há previsão.

\section{BIT Portugal - Brasil (1994)}

a) Critério “a” (TJE) - Há previsão de cláusula de tratamento justo e equitativo. Abrangência genérica.

b) Critério "b" (PSI) - Há previsão e cláusula de proteção e segurança dos investimentos.

c) Critério "c" (CGC) - Não há garantia de proteção por BIT em caso de descumprimento de contrato de investimentos.

d) Critério "d” (DES) - Há previsão de desapropriação direta e indireta e sua respectiva compensação.

e) Critério "e" (NMF) - Contempla isonomia em relação a tratamentos pré e pós-estabelecimento.

f) Critério "f" (CRS) - Não há previsão.

\section{BIT Venezuela - Brasil (1995)}

a) Critério “a” (TJE) - Há previsão de cláusula de tratamento justo e equitativo. Abrangência genérica.

b) Critério "b" (PSI) - Há previsão e cláusula de proteção e segurança dos investimentos.

c) Critério "c" (CGC) - Não há garantia de proteção por BIT em caso de descumprimento de contrato de investimentos. 
d) Critério "d" (DES) - Há previsão de desapropriação direta e indireta e sua respectiva compensação.

e) Critério "e" (NMF) - Contempla isonomia em relação a tratamentos pós-estabelecimento.

f) Critério “f” (CRS) - Não há previsão.

\section{Comparação sintética dos IIAs cujo Brasil figura como parte.}

\begin{tabular}{|c|c|c|c|c|c|c|}
\hline $\begin{array}{l}\text { BIT / } \\
\text { Critérios }\end{array}$ & TJE & PSI & CGC & DES & NMF & CRS \\
\hline $\begin{array}{l}\text { BIT } \\
\text { Angola } \\
\text { - Brasil } \\
(2015)\end{array}$ & Não & Não & Sim & $\begin{array}{l}\text { Apenas } \\
\text { direta }\end{array}$ & $\begin{array}{l}\text { Sim. } \\
\text { Pré e } \\
\text { pós. }\end{array}$ & $\begin{array}{l}\text { Sim. } \\
\text { Genérica. }\end{array}$ \\
\hline $\begin{array}{l}\text { BIT } \\
\text { Brasil } \\
\text { - Chile } \\
\text { (1994) }\end{array}$ & $\begin{array}{l}\text { Sim. } \\
\text { Genérica. }\end{array}$ & $\begin{array}{l}\text { Sim. } \\
\text { Genérica. }\end{array}$ & Não & $\begin{array}{l}\text { Apenas } \\
\text { direta }\end{array}$ & $\begin{array}{l}\text { Sim. } \\
\text { Apenas } \\
\text { pós. }\end{array}$ & Não \\
\hline $\begin{array}{l}\text { BIT } \\
\text { Brasil } \\
- \text { Chile } \\
(2015) \\
\end{array}$ & Não & Não & Não & $\begin{array}{l}\text { Apenas } \\
\text { direta. }\end{array}$ & $\begin{array}{l}\text { Sim. } \\
\text { Apenas } \\
\text { pós. }\end{array}$ & $\begin{array}{l}\text { Sim. } \\
\text { Detalhada }\end{array}$ \\
\hline $\begin{array}{l}\text { BIT } \\
\text { Brasil - } \\
\text { França } \\
(1995)\end{array}$ & $\begin{array}{l}\text { Sim. } \\
\text { Detalhada. }\end{array}$ & $\begin{array}{l}\text { Sim. } \\
\text { Genérica. }\end{array}$ & Não & $\begin{array}{l}\text { Sim. } \\
\text { Direta e } \\
\text { indireta. }\end{array}$ & $\begin{array}{l}\text { Sim. } \\
\text { Apenas } \\
\text { pós. }\end{array}$ & Não \\
\hline $\begin{array}{l}\text { BIT } \\
\text { Brasil - } \\
\text { Portugal } \\
(1994)\end{array}$ & $\begin{array}{l}\text { Sim. } \\
\text { Genérica. }\end{array}$ & $\begin{array}{l}\text { Sim. } \\
\text { Genérica. }\end{array}$ & Não & $\begin{array}{l}\text { Sim. } \\
\text { Direta e } \\
\text { indireta. }\end{array}$ & $\begin{array}{l}\text { Sim. } \\
\text { Pré e } \\
\text { pós. }\end{array}$ & Não \\
\hline \begin{tabular}{l|} 
BIT \\
Brasil - \\
Venezuela \\
BIT \\
$(1995)$
\end{tabular} & $\begin{array}{l}\text { Sim. } \\
\text { Genérica. }\end{array}$ & $\begin{array}{l}\text { Sim. } \\
\text { Genérica. }\end{array}$ & Não & $\begin{array}{l}\text { Sim. } \\
\text { Direta e } \\
\text { indireta. }\end{array}$ & $\begin{array}{l}\text { Sim. } \\
\text { Apenas } \\
\text { pós. }\end{array}$ & Não \\
\hline
\end{tabular}

\subsection{IIAs em que a Colômbia figura como parte}

\section{BIT Colômbia - Cuba ( 1994)}

a) Critério “a” (TJE) - Sim, há previsão de cláusula de tratamento justo e equitativo (Artigo 3 - Tratamento ao Investimento , item 1.)

b) Critério "b" (PSI) - Sim, há previsão de cláusula de proteção e segurança de investimentos (Artigo 3 Tratamento ao Investimento, itens 1. e 2.)

c) Critério "c" (CGC) - Sim, há garantia de proteção por BIT em caso de descumprimento de contrato de investimentos (Artigo 8 - Compensação por perdas, itens 1. e 2.)

d) Critério "d" (DES) - Cláusulas que desautoriza a nacionalização ou qualquer outra forma de expropriação, salvo se essas medidas se realizem de acordo com a
Constituição e com a lei, de maneira não discriminatória, por motivos de utilidade pública ou interesse social (Artigo 7 - Expropriação e medidas equivalentes, item 1.)

e) Critério "e" (NMF) - Sim, há previsão de cláusula da nação mais favorecida ( Artigo 4 - Tratamento Nacional e Cláusula da Nação mais Favorecida, item 1. e Artigo 11), com as exceções prevista no Artigo 5.

$$
\text { f) Critério "f” (CRS) - Não há previsão específica }
$$

\section{BIT Colômbia - Costa Rica (2013)}

a) Critério "a" (TJE) - Sim, há previsão de cláusula de tratamento justo e equitativo (Artigo 12.4) de forma bem genérica;

b) Critério "b" (PSI) - Sim, há previsão genérica de cláusula de proteção e segurança de investimentos;

c) Critério "c" (CGC) - Sim, há previsão de proteção em caso de descumprimento de contrato de investimentos.

d) Critério "d" (DES) - Sim, há cláusula vedando a nacionalização ou qualquer outra forma de expropriação (Artigo 12.11), salvo se por razões de ordem pública, de forma não discriminatória, com o pagamento de indenização e através do devido processo;

e) Critério "e" (NMF) - Sim, há previsão de cláusula da nação mais favorecida (Artigo 12.13), sem qualquer ressalva.

f) Critério "f " (CRS) - Sim, há cláusula de responsabilidade social (Artigo 12.9).

\section{BIT Colômbia - França (2014)}

a) Critério "a" (TJE) - Sim, há previsão de cláusula de tratamento justo e equitativo (Artigo 4 - Standard Mínimo de Tratamento, item 1.)

b) Critério "b" (PSI) - Sim, há previsão de cláusula de proteção e segurança de investimentos (Artigo 4 Standard Mínimo de Tratamento, item e 2.)

c) Critério "c" (CGC) - Sim, há garantia de proteção por BIT em caso de descumprimento de contrato de investimentos (Artigo 7 - Compensação por perdas)

d) Critério "d" (DES) - Cláusulas que desautoriza a nacionalização ou qualquer outra forma de expropria- 
ção, salvo por motivos de utilidade pública ou interesse social (Artigo 6 - Expropriação e Indenização, item 1.)

e) Critério "e" (NMF) - Sim, há previsão de cláusula da nação mais favorecida (Artigo 5 - Tratamento Nacional e Nação mais Favorecida, itens 1. ao 4.)

f) Critério "f f" (CRS) - Há previsão detalhada. Cláusulas que estipulam maior comprometimento possível dos investidores (Artigo 10 - Medidas relacionadas com o Meio Ambiente, a Saúde e os Direitos Laborais e Artigo 11 que prevê diretrizes sobre a Responsabilidade Social Corporativa).

\section{BIT Colômbia - Emirados Árabes Unidos (2017)}

a) Critério "a" (TJE) - Há previsão expressa de tratamento justo e equitativo na Cláusula 5.

b) Critério "b" (PSI) - Há previsão genérica de tratamento justo e equitativo na Cláusula 5.

c) Critério "c" (CGC) - Há garantia de proteção por BIT em caso de descumprimento de contrato de investimentos (Cláusulas 12 e 14).

d) Critério “d” (DES) - Há normatização sobre desapropriação, direta e indireta na Cláusula 7 e especificidade de situações normatizadas.

e) Critério "e" (NMF) - Há previsão expressa de Nação Mais Favorecida na Cláusula 4 (itens 1 a 5), contendo especificidades.

f) Critério " $\mathrm{f}$ ” (CRS) - Há previsão específica de responsabilidade Social (ambiental e trabalhista) na Cláusula 10

\section{Comparação sintética dos IIAs em que a Colôm- bia figura como parte}

\begin{tabular}{|c|c|c|c|c|c|c|}
\hline $\begin{array}{l}\text { BIT / } \\
\text { Critérios }\end{array}$ & TJE & PSI & CGC & DES & NMF & CRS \\
\hline $\begin{array}{l}\text { BIT } \\
\text { Colômbia } \\
\text { - Cuba } \\
(1994)\end{array}$ & $\begin{array}{l}\text { Sim. } \\
\text { Detalhada }\end{array}$ & $\begin{array}{l}\text { Sim. } \\
\text { Genérica }\end{array}$ & Sim & $\begin{array}{l}\text { Sim. Direta e } \\
\text { Indireta }\end{array}$ & Sim & Não \\
\hline \begin{tabular}{|l|} 
BIT \\
Colômbia \\
- Costa \\
Rica \\
$(2013)$ \\
\end{tabular} & Sim & $\begin{array}{l}\text { Sim. } \\
\text { Genérica }\end{array}$ & Sim & $\begin{array}{l}\text { Sim. Direta e } \\
\text { Indireta }\end{array}$ & Sim & Sim \\
\hline $\begin{array}{l}\text { BIT } \\
\text { Colômbia } \\
\text { - França } \\
\text { BIT } \\
(2014)\end{array}$ & $\begin{array}{l}\text { Sim. } \\
\text { Detalhada }\end{array}$ & $\begin{array}{l}\text { Sim. } \\
\text { Específica }\end{array}$ & Sim & $\begin{array}{l}\text { Sim. Direta e } \\
\text { Indireta }\end{array}$ & Sim & $\begin{array}{l}\text { Sim. } \\
\text { Específica }\end{array}$ \\
\hline
\end{tabular}

\begin{tabular}{|c|c|c|c|c|c|c|}
\hline $\begin{array}{l}\text { BIT / } \\
\text { Critérios }\end{array}$ & TJE & PSI & CGC & DES & NMF & CRS \\
\hline $\begin{array}{l}\text { BIT } \\
\text { Colômbia } \\
- \\
\text { Emirados } \\
\text { Árabes } \\
\text { Unidos } \\
\text { (2017) }\end{array}$ & $\begin{array}{l}\text { Sim. } \\
\text { Detalhada }\end{array}$ & $\begin{array}{l}\text { Sim. } \\
\text { Genérica }\end{array}$ & Sim & $\begin{array}{l}\text { Sim. Direta } \\
\text { e Indireta, } \\
\text { com especifici- } \\
\text { dades. }\end{array}$ & $\begin{array}{l}\text { Sim, com } \\
\text { especifici- } \\
\text { dades. }\end{array}$ & $\begin{array}{l}\text { Sim. } \\
\text { Especí- } \\
\text { fica. }\end{array}$ \\
\hline
\end{tabular}

\subsection{IIAs em que o Chile figura como parte}

\section{BIT Chile - Hungria (1997)}

a) Critério "a” (TJE) - Sim, há previsão de cláusula de tratamento justo e equitativo (Artigo 4 - Tratamento ao Investimento , item 1.)

b) Critério "b" (PSI) - Sim, há previsão de cláusula genérica de proteção e segurança de investimentos (Artigo 3 - Promoção e Proteção de Investimentos, item 2.)

c) Critério "c" (CGC) - Não há cláusula guarda-chuva

d) Critério “d” (DES) - Sim, há cláusula que desautoriza a nacionalização ou qualquer outra forma de expropriação, salvo por motivos de utilidade pública ou interesse social, vedado o tratamento discriminatório e mediante compensação imediata (Artigo 6 - Expropriação e Indenização, item 1.)

e) Critério "e" (NMF) - Sim, há previsão de cláusula da nação mais favorecida ( Artigo 4 - Tratamento Nacional e Nação mais Favorecida, itens 2 e 3)

f) Critério "f" (CRS) - Não há cláusula de responsabilidade social

\section{BIT Chile - Indonésia (1999)}

a) Critério "a” (TJE) - Sim, há previsão de cláusula de tratamento justo e equitativo (Artigo 4 - Tratamento ao Investimento , item 1.)

b) Critério "b" (PSI) - Sim, há previsão de cláusula genérica de proteção e segurança de investimentos (Artigo 3 - Promoção e Proteção de Investimentos, item 2.)

c) Critério "c" (CGC) - Sim, há garantia de proteção por BIT em caso de descumprimento de contrato de investimentos (Artigo 7 - Compensação por perdas)

d) Critério "d" (DES) - Sim, há cláusula que desautoriza a nacionalização ou qualquer outra forma de expropriação, salvo por motivos de utilidade pública ou 
interesse social, vedado o tratamento discriminatório e mediante compensação imediata (Artigo 6 - Expropriação e Indenização, item 1.)

e) Critério "e" (NMF) - Sim, há previsão de cláusula da nação mais favorecida (Artigo 4 - Tratamento Nacional e Nação mais Favorecida, itens 2 e 3)

f) Critério "f” (CRS) - Não há cláusula de responsabilidade social

\section{BIT Chile - Hong Kong (2016)}

a) Critério "a" (TJE) - Sim, há previsão de cláusula de tratamento justo e equitativo (Artigo 6 - Minimum Standard of Treatment, item 1.)

b) Critério "b" (PSI) - Sim, há previsão de cláusula de proteção e segurança de investimentos (Artigo 6 Minimum Standard of Treatment, item 2.)

c) Critério "c" (CGC) - Sim, há garantia de proteção por BIT em caso de descumprimento de contrato de investimentos (Artigo 7 - Tratamento em caso de conflito armado ou guerra civil)

d) Critério "d" (DES) - Sim, há cláusula que desautoriza a nacionalização ou qualquer outra forma de expropriação, salvo por motivos de utilidade pública ou interesse social, vedado o tratamento discriminatório e mediante devido processo legal e compensação imediata (Artigo 10 - Expropriação, item 1.)

e) Critério "e" (NMF) - Não há cláusula de nação mais favorecida

f) Critério "f” (CRS) - Não há cláusula de responsabilidade social.

\section{Free Trade Agreement - Argentina - Chile (2017)}

a) Critério "a" (TJE) - Sim, há previsão de cláusula de tratamento justo e equitativo (Artigo 8.7) de forma bem genérica;

b) Critério "b" (PSI) - Sim, há previsão genérica de proteção e segurança de investimentos;

c) Critério "c" (CGC) - Sim, há previsão de proteção em caso de descumprimento de contrato de investimentos (Artigo 8.36).

d) Critério "d" (DES) - Sim, há cláusula vedando a nacionalização ou qualquer outra forma de expropria- ção (Artigo 8.8), salvo se por razões de ordem pública, de forma não discriminatória, com o pagamento de indenização e através do devido precesso;

e) Critério "e” (NMF) - Sim, há previsão de cláusula da nação mais favorecida (Artigo 8.6), sem qualquer ressalva.

f) Critério "f" (CRS) - Sim, há cláusula de responsabilidade social (Artigo 8.17).

\section{Comparação sintética dos IIAs em que o Chile fi- guram como parte.}

\begin{tabular}{|c|c|c|c|c|c|c|}
\hline $\begin{array}{l}\text { BIT / } \\
\text { Critérios }\end{array}$ & TJE & PSI & CGC & DES & NMF & CRS \\
\hline $\begin{array}{l}\text { BIT Chile } \\
\text { - Hungria } \\
(1997) \\
\end{array}$ & $\begin{array}{l}\text { Sim. } \\
\text { Genérica }\end{array}$ & $\begin{array}{l}\text { Sim. } \\
\text { Genérica }\end{array}$ & Não & $\begin{array}{l}\text { Sim. } \\
\text { Direta e } \\
\text { Indireta }\end{array}$ & Sim. & Não \\
\hline $\begin{array}{l}\text { BIT Chile } \\
\text { - Indonésia } \\
(1999)\end{array}$ & $\begin{array}{l}\text { Sim. } \\
\text { Genérica }\end{array}$ & $\begin{array}{l}\text { Sim. } \\
\text { Genérica }\end{array}$ & Sim & $\begin{array}{l}\text { Sim. } \\
\text { Direta e } \\
\text { Indireta }\end{array}$ & Sim & Não \\
\hline $\begin{array}{l}\text { BIT Chile - } \\
\text { Hong Kong } \\
\text { (2016) }\end{array}$ & $\begin{array}{l}\text { Sim. } \\
\text { Detalhada }\end{array}$ & $\begin{array}{l}\text { Sim. } \\
\text { Genérica }\end{array}$ & Sim & $\begin{array}{l}\text { Sim. } \\
\text { Direta e } \\
\text { Indireta }\end{array}$ & Não & $\begin{array}{l}\text { Sim. } \\
\text { Genérica }\end{array}$ \\
\hline $\begin{array}{l}\text { Free Trade } \\
\text { Agreement } \\
\text { - Argentina } \\
\text { e Chile } \\
(2017)\end{array}$ & $\begin{array}{l}\text { Sim. } \\
\text { Genérica }\end{array}$ & $\begin{array}{l}\text { Sim. } \\
\text { Genérica }\end{array}$ & Sim & $\begin{array}{l}\text { Sim. } \\
\text { Direta e } \\
\text { Indireta }\end{array}$ & Sim & Sim \\
\hline
\end{tabular}

\subsection{IIAs em que Comunidade Andina figura como parte}

\section{Trade and Investment Cooperation Arrange- ment - Comunidade Andina e Canada (1999)}

a) Critério “a” (TJE) - Não há previsão de cláusula de tratamento justo e equitativo.

b) Critério "b" (PSI) - Não há previsão de cláusula de proteção e segurança de investimentos.

c) Critério "c" (CGC) - Não há previsão de proteção em caso de descumprimento de contrato de investimentos.

d) Critério "d" (DES) - Não há cláusula que desautoriza a nacionalização ou qualquer outra forma de expropriação.

e) Critério "e" (NMF) - Não há cláusula de nação mais favorecida

f) Critério "f" (CRS) - Não há cláusula de responsabilidade social. 
Political Dialogue and Co-operation Agreement - Comunidade Andina e Comunidade Europeia (2003)

a) Critério “a” (TJE) - Não há previsão de cláusula de tratamento justo e equitativo.

b) Critério "b" (PSI) - Não há previsão de cláusula de proteção e segurança de investimentos.

c) Critério "c" (CGC) - Não há previsão de proteção em caso de descumprimento de contrato de investimentos.

d) Critério "d" (DES) - Não há cláusula que desautoriza a nacionalização ou qualquer outra forma de expropriação.

e) Critério "e" (NMF) - Não há cláusula de nação mais favorecida

f) Critério "f” (CRS) - Não há cláusula de responsabilidade social.

\section{Comprehensive and Progressive Agreement for Trans-Pacific Partnership (CPTPP) (2018)}

a) Critério “a” (TJE) - Sim, há previsão de cláusula de tratamento justo e equitativo (Artigo 9.6). O item 1 traz a proteção de acordo com o direito internacional aplicável, porém, nos itens seguintes, há uma preocupação em limitar a abrangência do FET, ressalvando que eventuais condutas dos Estados que sejam contrárias ao investidor ou até mesmo revogação ou não prorrogação de determinado subsídio não pode ser considerada quebra do tratamento justo e equitativo.

b) Critério "b" (PSI) - Sim, há previsão de cláusula de proteção e segurança de investimentos (Artigo 9.6) junto com a proteção ao tratamento justo e equitativo, no artigo que trata do standard mínimo de proteção.

c) Critério "c" (CGC) - Sim, há previsão de proteção em caso de descumprimento de contrato de investimentos, mas somente em relação ao descumprimento dos critérios a e b (Artigo 9.6, item 3).

d) Critério "d" (DES) - Sim, há cláusula vedando a nacionalização ou qualquer outra forma de expropriação (Artigo 9.8), salvo se por razões de ordem pública, de forma não discriminatória, com o pronto pagamento de adequada e efetiva indenização e de acordo com o devido processo legal. e) Critério "e" (NMF) - Sim, há previsão de cláusula da nação mais favorecida (Artigo 9.5), fazendo ressalva expressa para não incluir nessa cláusula as normas procedimentais de resolução de conflitos.

f) Critério " $f$ " (CRS) - Há cláusula de responsabilidade social apenas reafirmando que as partes encorajam que as empresas operem de acordo com os standards internacionalmente reconhecidos e princípios de responsabilidade social, não trazendo qualquer sanção ou detalhamento sobre o tema.

\section{Comparação sintética dos IIAs em que Comuni- dade Andina figura como parte.}

\begin{tabular}{|l|l|l|l|l|l|l|}
\hline $\begin{array}{l}\text { BIT / } \\
\text { Critérios }\end{array}$ & TJE & PSI & CGC & DES & NMF & CRS \\
\hline $\begin{array}{l}\text { ANCOM- } \\
\begin{array}{l}\text { Canada } \\
(1999)\end{array}\end{array}$ & Não & Não & Não & Não & Não & Não \\
\hline $\begin{array}{l}\text { ANCOM- } \\
\text { EC } \\
(2003)\end{array}$ & Não & Não & Não & Não & Não & Não \\
\hline $\begin{array}{l}\text { CPTPP } \\
(2018)\end{array}$ & Sim & Sim & Sim & Sim & Sim & Sim \\
\hline
\end{tabular}

\subsection{IIAs em que o Uruguai figura como parte}

\section{BIT Índia-Uruguai (2008)}

a) Critério "a" (TJE) - Sim, há previsão de cláusula de tratamento justo e equitativo (Artigo 3, item 2).

b) Critério "b" (PSI) - Não há previsão de cláusula de proteção e segurança de investimentos.

c) Critério "c" (CGC) - Não há previsão de proteção em caso de descumprimento de contrato de investimentos.

d) Critério "d" (DES) - Sim, há cláusula que desautoriza a nacionalização ou qualquer outra forma de expropriação (Artigo 5).

e) Critério "e" (NMF) - Sim, há previsão de cláusula da nação mais favorecida (Artigo 4).

f) Critério "f" (CRS) - Não há cláusula de responsabilidade social.

\section{BIT Japão-Uruguai (2015)}

a) Critério "a" (TJE) - Sim, há previsão de cláusula de tratamento justo e equitativo (Artigo 5, item 1). 
b) Critério "b" (PSI) - Sim, há previsão de cláusula de proteção e segurança de investimentos (Artigo 5, item 1).

c) Critério "c" (CGC) - Sim, há parcial previsão de proteção em caso de descumprimento de contrato de investimentos, mas somente em relação ao descumprimento dos critérios a e b (Artigo 5, item 3).

d) Critério "d" (DES) - Sim, há cláusula que desautoriza a nacionalização ou qualquer outra forma de expropriação (Artigo 16).

e) Critério "e” (NMF) - Sim, há previsão de cláusula da nação mais favorecida (Artigo 4).

f) Critério "f" (CRS) - Sim, há parcial previsão de cláusula de responsabilidade social em relação a transparência, medidas anti-corrupção, e padrões trabalhistas e medidas de saúde, segurança e ambientais (Artigos $11,15$ e 27$)$.

\section{Comparação sintética dos BITs em que o Uruguai figura como parte.}

\begin{tabular}{|l|l|l|l|l|l|l|}
\hline $\begin{array}{l}\text { BIT / } \\
\text { Critérios }\end{array}$ & TJE & PSI & CGC & DES & NMF & CRS \\
\hline $\begin{array}{l}\text { BIT Î́ndia- } \\
\begin{array}{l}\text { Uruguai } \\
\text { (2008) }\end{array}\end{array}$ & Sim & Não & Não & Sim & Sim & Não \\
\hline $\begin{array}{l}\text { BIT Japão- } \\
\begin{array}{l}\text { Uruguai } \\
\text { (2015) }\end{array}\end{array}$ & Sim & Sim & $\begin{array}{l}\text { Sim, } \\
\text { parcial. }\end{array}$ & Sim & Sim & Sim, parcial. \\
\hline
\end{tabular}

\subsection{IIAs em que a Venezuela figura como parte}

\section{BIT Italia-Venezuela (1990)}

a) Critério "a” (TJE) - Sim, há previsão de cláusula de tratamento justo e equitativo (Artigo 2, item 2).

b) Critério "b" (PSI) - Não há previsão de cláusula de proteção e segurança de investimentos.

c) Critério "c" (CGC) - Não há previsão de proteção em caso de descumprimento de contrato de investimentos.

d) Critério "d" (DES) - Sim, há cláusula que desautoriza a nacionalização ou qualquer outra forma de expropriação (Artigo 5).

e) Critério "e" (NMF) - Sim, há previsão de cláusula da nação mais favorecida (Artigo 3). f) Critério "f" (CRS) - Não há cláusula de responsabilidade social.

\section{BIT Venezuela-Vietnam (2008)}

a) Critério "a” (TJE) - Sim, há previsão de cláusula de tratamento justo e equitativo (Artigo 2, item 2).

b) Critério "b" (PSI) - Sim, há previsão de cláusula de proteção e segurança de investimentos (Artigo 2, item 2).

c) Critério "c" (CGC) - Não há previsão de proteção em caso de descumprimento de contrato de investimentos.

d) Critério "d" (DES) - Sim, há cláusula que desautoriza a nacionalização ou qualquer outra forma de expropriação (Artigo 5).

e) Critério "e" (NMF) - Sim, há previsão de cláusula da nação mais favorecida (Artigo 3).

f) Critério "f" (CRS) - Não há cláusula de responsabilidade social

\section{Comparação sintética dos IIAs em que a Vene- zuela figura como parte.}

\begin{tabular}{|l|l|l|l|l|l|l|}
\hline $\begin{array}{l}\text { BIT / } \\
\text { Critérios }\end{array}$ & TJE & PSI & CGC & DES & NMF & CRS \\
\hline $\begin{array}{l}\text { BIT Itália- } \\
\text { Venezuela } \\
(1990)\end{array}$ & Sim & Não & Não & Sim & Sim & Não \\
\hline $\begin{array}{l}\text { BIT } \\
\text { Venezuela- } \\
\begin{array}{l}\text { Vietnam } \\
(2008)\end{array}\end{array}$ & Sim & Sim & Não & Sim & Sim & Não \\
\hline
\end{tabular}

\subsection{Outros bits firmados por países latino- americanos}

\section{BIT Bolívia - Costa Rica (2002)}

a) Critério "a" (TJE) - Sim, há previsão de cláusula de tratamento justo e equitativo ( Artigo II - Promoção de Investimentos, item 1.)

b) Critério "b” (PSI) - Sim, há previsão de cláusula de proteção e segurança de investimentos (Artigo III Proteção dos investimentos: trato nacional e da nação mais favorecida, item 1.) 
c) Critério "c" (CGC) - Sim, há garantia de proteção por BIT em caso de descumprimento de contrato de investimentos

d) Critério "d" (DES) - Cláusula que desautoriza casos de desapropriação indireta. Contudo, estipula-se compensação justa no caso de "expropriação por utilidade pública” (Artigo IV - Expropriação e Indenização , item 1.)

e) Critério "e" (NMF) - Sim, há previsão de cláusula da nação mais favorecida. (Artigo III - Proteção dos investimentos: trato nacional e da nação mais favorecida, item 2.)

f) Critério “f” (CRS) - Não há previsão específica

\section{BIT Argentina - Nova Zelândia (1999)}

a) Critério "a" (TJE) - Sim, há previsão de cláusula de tratamento justo e equitativo (Artigo 3, item 2) de forma bem genérica no capítulo referente a admissão, promoção e proteção dos investimentos.

b) Critério "b" (PSI) - Não há previsão de cláusula de proteção e segurança de investimentos de forma expressa. A proteção maior se dá no artigo 3 , que trata de encorajamento, criação de condições favoráveis e proteção aos investimentos (com foco no tratamento justo e equitativo no item 2)

c) Critério "c" (CGC) - Não há previsão de proteção em caso de descumprimento de contrato de investimentos.

d) Critério "d” (DES) - Sim, há cláusula vedando a nacionalização ou qualquer outra forma de expropriação (Artigo 6), salvo se por razões de ordem pública, de forma não discriminatória, com o pronto pagamento de adequada e efetiva indenização.

e) Critério "e" (NMF) - Sim, há previsão de cláusula da nação mais favorecida, ressalvando apenas o marco temporal, ou seja, após o estabelecimento do investimento (Artigo 4).

f) Critério "f” (CRS) - Não há cláusula de responsabilidade social.
Comparação sintética de outros IIAs firmados por países latino-americanos.

\begin{tabular}{|l|l|l|l|l|l|l|}
\hline $\begin{array}{l}\text { BIT / } \\
\text { Critérios }\end{array}$ & TJE & PSI & CGC & DES & NMF & CRS \\
\hline $\begin{array}{l}\text { BIT Bolívia } \\
\text { - Costa } \\
\text { Rica (2002) }\end{array}$ & $\begin{array}{l}\text { Sim. } \\
\text { Deta- } \\
\text { lhada }\end{array}$ & $\begin{array}{l}\text { Sim. } \\
\text { Genérica }\end{array}$ & Sim & $\begin{array}{l}\text { Sim. } \\
\text { Direta e } \\
\text { Indireta }\end{array}$ & Sim. & Não \\
\hline $\begin{array}{l}\text { BIT } \\
\text { Argentina- } \\
\begin{array}{l}\text { Nova } \\
\text { Zelândia } \\
(1999)\end{array}\end{array}$ & Sim. & $\begin{array}{l}\text { Não de } \\
\text { forma } \\
\text { expressa }\end{array}$ & Não & Sim. & Sim & Não \\
\hline
\end{tabular}

\subsection{IIAs firmados por estados da America Central}

\section{BIT Barbados - BLEU (Belgium-Luxembourg Eco- nomic Union) (2009))}

a) Critério "a" (TJE) - Sim, há previsão de cláusula de tratamento justo e equitativo (Artigo 2, item 2) de forma bem genérica.

b) Critério "b" (PSI) - Sim, há previsão de cláusula de proteção e segurança de investimentos (Artigo 2, item 2)

c) Critério "c" (CGC) - Não há previsão de proteção em caso de descumprimento de contrato de investimentos.

d) Critério "d" (DES) - Sim, há cláusula vedando a nacionalização ou qualquer outra forma de expropriação (Artigo 5), salvo se por razões de ordem pública, de forma não discriminatória, com o pronto pagamento de adequada e efetiva.

e) Critério "e" (NMF) - Sim, há previsão de cláusula da nação mais favorecida (Artigo 3), sem qualquer ressalva.

f) Critério "ff" (CRS) - Não há cláusula de responsabilidade social.

\section{BIT Costa Rica - El Salvador (2018)}

a) Critério "a" (TJE) - Sim, há previsão de cláusula de tratamento justo e equitativo (artigo 2).

b) Critério "b" (PSI) - Sim, há previsão de cláusula de proteção e segurança de investimentos de forma expressa. 
c) Critério "c" (CGC) - Não há previsão de proteção em caso de descumprimento de contrato de investimentos.

d) Critério "d" (DES) - Sim, há cláusula vedando a nacionalização ou qualquer outra forma de expropriação (Artigo 3), salvo se por razões de ordem pública, de forma não discriminatória, mediante o pagamento de uma compensação rápida, adequada e eficaz.

e) Critério “e” (NMF) - Sim, há previsão de cláusula da nação mais favorecida (Artigo 9.4).

f) Critério "f" (CRS) - Não há cláusula de responsabilidade social.

\section{BIT Guiana - Suíça (2005)}

a) Critério "a" (TJE) - Há previsão expressa de tratamento justo e equitativo na Cláusula 4, item 1.

b) Critério "b" (PSI) - Há previsão genérica de tratamento justo e equitativo na Cláusula 4.

c) Critério "c" (CGC) - Há garantia de proteção por BIT em caso de descumprimento de contrato de investimentos (Cláusulas 08 e 09).

d) Critério "d" (DES) - Há normatização sobre desapropriação, direta e indireta na Cláusula 6 sem detalhamento.

e) Critério "e" (NMF) - Não há previsão expressa de Cláusula da Nação Mais Favorecida.

f) Critério “f” (CRS) - Não há Cláusula de Responsabilidade Social.

\section{BIT Indonésia - Jamaica (1999)}

a) Critério “a” (TJE) - Há previsão expressa de tratamento justo e equitativo na Cláusula 2, item 2 e na Cláusula 3, item 1.

b) Critério "b" (PSI) - Há previsão genérica de tratamento de proteção e segurança dos investimentos na Cláusula 3, item 2.

c) Critério "c" (CGC) - Há garantia de proteção por BIT em caso de descumprimento de contrato de investimentos (Cláusulas 08, 09 e 10).

d) Critério "d" (DES) - Há normatização sobre desapropriação, sem referência expressa se direta ou indireta na Cláusula 4 e sem especificidade de situações normatizadas.

e) Critério "e" (NMF) - Há previsão expressa de Nação Mais Favorecida na Cláusula 3 (itens 1 a 4), contendo especificidades.

f) Critério "f " (CRS) - Não há Cláusula de Responsabilidade Social.

\section{Free Trade Agreement - CACM X República Domi- nicana (1998)}

a) Critério "a” (TJE) - Há previsão expressa de tratamento justo e equitativo na Cláusula 9.03.

b) Critério "b" (PSI) - Há previsão genérica na Cláusula 9.03.

c) Critério "c" (CGC) - Há garantia de proteção por BIT em caso de descumprimento de contrato de investimentos, inclusive trata da solução de controvérsias (Cláusulas 9.06 e 9.20).

d) Critério "d" (DES) - Há normatização sobre desapropriação, direta e indireta na Cláusula 9.11 e especificidade de situações normatizadas.

e) Critério "e" (NMF) - Há previsão expressa de Nação Mais Favorecida na Cláusula 9.05

f) Critério "f" (CRS) - Há previsão específica de responsabilidade Social (ambiental) na Cláusula 9.15.

\section{Free Trade Agreement - CACM X Panamá (2002)}

a) Critério "a” (TJE) - Há previsão expressa de tratamento justo e equitativo na Cláusula 10.6.

b) Critério "b" (PSI) - Há previsão expressa, porém génerica juntamente com o tratamento justo e equitativo na Cláusula 10.6.

c) Critério "c" (CGC) - Há garantia de proteção por BIT em caso de descumprimento de contrato de investimentos (Cláusulas 10.10 e 10.35).

d) Critério "d" (DES) - Há normatização sobre desapropriação, direta e indireta na Cláusula 10.11 com detalhamento das situações.

e) Critério "e" (NMF) - Há previsão expressa de Cláusula da Nação Mais Favorecida na cláusula 10.03.

f) Critério “f” (CRS) - Há previsão específica de responsabilidade Social (ambiental) na Cláusula 10.15. 


\section{Free Trade Agreement - CACM X México (2011)}

a) Critério “a” (TJE) - Há previsão expressa e detalhada de tratamento justo e equitativo na Cláusula 11.3

b) Critério "b" (PSI) - Há previsão expressa e detalhada de proteção e segurança na Cláusula 11.3

c) Critério "c" (CGC) - Há garantia genérica de proteção por BIT em caso de descumprimento de contrato de investimentos (Cláusula 11.10).

d) Critério “d” (DES) - Há normatização sobre desapropriação, direta ou indireta na Cláusula 11.11 com especificidade de situações normatizadas.

e) Critério "e" (NMF) - Há previsão expressa de Nação Mais Favorecida na Cláusula 11.5, contendo especificidades.

f) Critério "f" (CRS) - Há previsão específica de responsabilidade Social (ambiental) na Cláusula 11.16.

\section{BIT Costa Rica - Reino Unido (1982)}

a) Critério "a" (TJE) - Não há previsão de cláusula de tratamento justo e equitativo.

b) Critério "b" (PSI) - Sim, há previsão de cláusula genérica de proteção e segurança de investimentos (Artigo II - 1, 2 e 3 - Fomento e protecion de inversiones)

c) Critério "c" (CGC) - Não há cláusula guarda-chuva

d) Critério "d" (DES) - Sim, há cláusula que desautoriza a nacionalização ou qualquer outra forma de expropriação, salvo por razones de uso público relacionado con las

necesidades internas de dicha Parte contratante y a cambio de compensación puntual, adecuaday efectiva". Artigo IV e V - Expropriação e Indenização por perdas)

e) Critério "e” (NMF) - Sim, há previsão de cláusula da nação mais favorecida ( Artigo III - Trato nacional y cláusula de la nación más favorecida

f) Critério "f" (CRS) - Não há cláusula de responsabilidade social

\section{BIT Cuba - Dinamarca (2001)}

a) Critério "a” (TJE) - Sim, há previsão de cláusula de tratamento justo e equitativo (Artigo 4 - Tratamento ao Investimento .

b) Critério "b" (PSI) - Sim, há previsão de cláusula genérica de proteção e segurança de investimentos (Artigo 2)

c) Critério "c" (CGC) - Não há cláusula guarda-chuva

d) Critério "d" (DES) - Sim, há cláusula que desautoriza a nacionalização ou qualquer outra forma de expropriação, salvo exceto para desapropriações feitas para o público, necessidade nacional ou social, com base na não discriminação, realizada sob o devido processo legal, e contra pronta, compensação adequada e eficaz. Previsão de compensação pronta, adequada e eficaz para esses investidores para qualquer imparidade ou diminuição do justo valor de mercado tal investimento resultante da expropriação. (Artigo 6)

e) Critério "e" (NMF) - Sim, há previsão de cláusula da nação mais favorecida, porém com indicação de exceções para que não seja interpretada de obrigar uma parte contratante a alargar aos investidores da outra parte Contratante o benefício de qualquer tratamento, preferência ou privilégio ( Artigo 4 e 5).

f) Critério "f $f$ " (CRS) - Não há cláusula de responsabilidade social

\section{Comparação sintética dos IIAs firmados por Esta- dos da America Central}

\begin{tabular}{|l|l|l|l|l|l|l|}
\hline $\begin{array}{l}\text { BIT / } \\
\text { Critérios }\end{array}$ & TJE & PSI & CGC & DES & NMF & CRS \\
\hline $\begin{array}{l}\text { BIT } \\
\text { Barbados } \\
\text { - BLEU } \\
(2009)\end{array}$ & Sim & Sim. & Não & Sim. & Sim. & Não \\
\hline $\begin{array}{l}\text { BIT Costa } \\
\text { Rica - El } \\
\text { Salvador } \\
(2018)\end{array}$ & Sim & Sim. & Não & Sim & Sim & Não \\
\hline $\begin{array}{l}\text { BIT Guiana } \\
- \text { Suíça } \\
(2005)\end{array}$ & $\begin{array}{l}\text { Sim. } \\
\text { Deta- } \\
\text { lhada }\end{array}$ & $\begin{array}{l}\text { Sim. } \\
\text { rica }\end{array}$ & Sim & $\begin{array}{l}\text { Indireta, } \\
\text { sem } \\
\text { detalha- } \\
\text { mentos. }\end{array}$ & Não. & Não \\
\hline $\begin{array}{l}\text { BIT } \\
\text { Indonésia } \\
- \text { Jamaica } \\
\text { (1999) }\end{array}$ & $\begin{array}{l}\text { Sim. } \\
\text { Gené- } \\
\text { rica. }\end{array}$ & $\begin{array}{l}\text { Sim. } \\
\text { Gené- } \\
\text { rica }\end{array}$ & Sim & $\begin{array}{l}\text { Sim. } \\
\text { Direta, } \\
\text { sem } \\
\text { detalha- } \\
\text { mentos. }\end{array}$ & $\begin{array}{l}\text { Sim, com } \\
\text { especifici- } \\
\text { dades. }\end{array}$ & Não \\
\hline
\end{tabular}




\begin{tabular}{|l|l|l|l|l|l|l|}
\hline $\begin{array}{l}\text { BIT / } \\
\text { Critérios }\end{array}$ & TJE & PSI & CGC & DES & NMF & CRS \\
\hline $\begin{array}{l}\text { CACM X } \\
\text { República } \\
\text { Dominicana } \\
(1998)\end{array}$ & $\begin{array}{l}\text { Sim. } \\
\text { Deta- } \\
\text { lhada }\end{array}$ & $\begin{array}{l}\text { Sim. } \\
\text { Gené- } \\
\text { rica }\end{array}$ & Sim & $\begin{array}{l}\text { Sim. } \\
\text { Direta e } \\
\text { Indireta, } \\
\text { com } \\
\text { detalha- } \\
\text { mentos. }\end{array}$ & Sim. & $\begin{array}{l}\text { Sim. } \\
\text { Ambiental }\end{array}$ \\
\hline $\begin{array}{l}\text { CACM X } \\
\text { Panamá } \\
\text { (2002) }\end{array}$ & $\begin{array}{l}\text { Sim. } \\
\text { Deta- } \\
\text { lhada }\end{array}$ & $\begin{array}{l}\text { Sim. } \\
\text { Gené- } \\
\text { rica }\end{array}$ & Sim & $\begin{array}{l}\text { Sim. } \\
\text { Direta e } \\
\text { com } \\
\text { cetalha- } \\
\text { mentos. }\end{array}$ & Sim. & $\begin{array}{l}\text { Sim. } \\
\text { Ambiental }\end{array}$ \\
\hline $\begin{array}{l}\text { CACM X } \\
\text { México } \\
\text { (2011) }\end{array}$ & $\begin{array}{l}\text { Sim. } \\
\text { Deta- } \\
\text { hada }\end{array}$ & $\begin{array}{l}\text { Sim. } \\
\text { Deta- } \\
\text { lhada }\end{array}$ & Sim & $\begin{array}{l}\text { Sim. } \\
\text { Direta e } \\
\text { indireta, } \\
\text { com } \\
\text { detalha- } \\
\text { mentos. }\end{array}$ & Sim. & $\begin{array}{l}\text { Sim. } \\
\text { Ambiental }\end{array}$ \\
\hline $\begin{array}{l}\text { BIT Costa } \\
\text { Rica- } \\
\text { United } \\
\begin{array}{l}\text { Kingdom } \\
\text { (1982) }\end{array}\end{array}$ & Não & Sim & Não & Sim & Sim & Não \\
\hline $\begin{array}{l}\text { BIT Cuba- } \\
\text { (2001) }\end{array}$ & Simarca & Sim & Não & Sim & Sim & Não \\
\hline
\end{tabular}

\subsection{Mercosul (Mercado Comum Sulamericano)}

\section{Framework Agreement. Egito - Mercosur (2004)}

a) Critério “a” (TJE) - Não há previsão de cláusula de tratamento justo e equitativo.

b) Critério "b" (PSI) - Não há previsão e cláusula de proteção e segurança dos investimentos.

c) Critério "c" (CGC) - Não há garantia de proteção por BIT em caso de descumprimento de contrato de investimentos.

d) Critério "d" (DES) - Não há previsão de desapropriação e sua respectiva compensação. Não há explicitação de casos de desapropriação indireta.

e) Critério “e” (NMF) - Não há previsão de isonomia.

f) Critério "f”" (CRS) - Não há previsão de responsabilidade social.

\section{MERCOSUR Investment Protocol (intra) (1994)}

http://investmentpolicyhub.unctad.org/Download/TreatyFile/3585

a) Critério "a" (TJE) - Há previsão de cláusula de tratamento justo e equitativo. (Art. 3)

b) Critério "b" (PSI) - Há previsão desta cláusula de proteção de investimentos. (Art. 6).

c) Critério "c" (CGC) - Não há garantia de proteção por BIT em caso de descumprimento de contrato de investimentos.

d) Critério "d” (DES) - Há previsão de desapropriação somente na hipótese de tal medida ser tomada em razão de interesse público. Neste caso, haverá compensação prévia correspondente ao valor real avaliado imediatamente antes da desapropriação. (Art. 4)

e) Critério "e" (NMF) - Contempla isonomia em relação a tratamentos pós-estabelecimento. (Art. 2)

f) Critério "f" (CRS) - Não há previsão de responsabilidade social.

\section{MERCOSUR Investment Protocol (extra). (1994)}

a) Critério “a” (TJE) - Há previsão de cláusula de tratamento justo e equitativo. [C) Proteccion de Inversiones, 1]

b) Critério "b” (PSI) - Há previsão e cláusula de proteção e segurança dos investimentos. [F) Subrogación]

c) Critério "c" (CGC) - Não há garantia de proteção por BIT em caso de descumprimento de contrato de investimentos.

d) Critério "d" (DES) - Há previsão de desapropriação e sua respectiva compensação, que será feita no valor correspondente ao valor real do objeto desapropriado. [D) Expropiaciones y Compensaciones]

e) Critério "e" (NMF) - Contempla isonomia em relação a tratamentos pós-estabelecimento. [C) Proteccion de Inversiones, 2]

f) Critério "f" (CRS) - Não há previsão de responsabilidade social dos investidores.

\section{Intra-MERCOSUR Investment Facilitation Protocol (2017)}

a) Critério "a" (TJE) - Os padrões de "tratamento justo e equitativo" e de "plena segurança e proteção" não são cobertos por esse Protocolo. (Parte II - Disposições de Tratamento e Medidas Regulatórias, Artigo $4^{\circ}$, 
3), embora haja previsão de tratamento não discriminatório (Parte II, Artigo 5\%).

b) Critério "b” (PSI) - Não há previsão e cláusula de proteção e segurança dos investimentos.

c) Critério "c" (CGC) - Não há garantia de proteção por BIT em caso de descumprimento de contrato de investimentos.

d) Critério “d” (DES) - Há previsão de desapropriação direta, a qual deve ser compensada com o valor justo de mercado do investimento desapropriado. (Parte II, Atigo $6^{\circ}$ ).

e) Critério "e" (NMF) - Não há previsão de isonomia .

f) Critério "f " (CRS) - Há previsão detalhada. (Parte II, Artigo 14)

\section{Comparação sintética de IIAs do Mercosul}

\begin{tabular}{|l|l|l|l|l|l|l|}
\hline $\begin{array}{l}\text { BIT / } \\
\text { Critérios }\end{array}$ & TJE & PSI & CGC & DES & NMF & CRS \\
\hline $\begin{array}{l}\text { Framemork } \\
\text { Agreement } \\
\text { Egito- } \\
\text { Mercosul } \\
\text { (2004) }\end{array}$ & Não & Não & Não & Não & Não & Não \\
\hline $\begin{array}{l}\text { Investment } \\
\text { Protocol } \\
\text { intra } \\
(1994)\end{array}$ & Sim & Sim & Não & Sim & Sim & Não \\
\hline $\begin{array}{l}\text { Investment } \\
\begin{array}{l}\text { Protocol } \\
\text { (extra) } \\
8 / 5 / 1994\end{array}\end{array}$ & Sim & Sim & Não & Sim & Sim & Não \\
\hline $\begin{array}{l}\text { Investment } \\
\text { Facilitation } \\
\begin{array}{l}\text { Protocol } \\
(2017)\end{array}\end{array}$ Não & Não & Não & Sim & Não & Sim \\
\hline
\end{tabular}

\section{A falta de padrões nos acordos de proteção de investimentos estrangeiros firmados pelos países latinoamericanos e da América Central}

Foi realizado o exame dos Acordos de Investimentos Internacionais (IIAs) celebrados por países latino-americanos e da América Central e a comparação entre grupos de tratados com a finalidade de identificar possíveis tendências e uniformizações entre os assuntos mais comumente levantados em sede de solução de conflitos internacionais envolvendo investimentos estrangeiros.

Após o mapeamento com base nos IIAs assinados entre 1990 e 2018, conforme escopo apresentado anteriormente, não foi possível concluir pela existência de algum modelo de acordo ou de padronização de cláusulas nos tratados internacionais de proteção ao investimento estrangeiro pesquisados.

De forma geral, a conclusão resultante da interseção dos IIAs analisados demonstrou que não houve, nem década de 1990, nem tampouco há, atualmente, um modelo padronizado de acordo internacional adotado pelos países da região.

A hipótese que pode explicar esta ausência de padrão de acordo internacional de proteção de investimentos nos países latino-americanos é que são em sua maioria grandes importadores de capital estrangeiro com pouco poder de negociação no cenário internacional. Nesta condição, estão muito mais suscetíveis às imposições dos países que proporcionam os investimentos e que possuem posição de negociação mais favorável. Entretanto, esta hipótese não foi testada ou aprofundada para permitir afirmar sua confirmação categórica.

De outro lado, os IIAs firmados por Estados da America Central e do Sul vêm sofrendo modificações recentemente, tendência que se projeta também para os próximos anos. Primeiro, em razão das diversas demandas arbitrais que surgiram ao longo dos anos, chamando a atenção para muitos assuntos que não eram previstos nos tratados e até mesmo para um maior debate que envolva as especificidades de cada país.

Essa é uma tendência que vem sendo capitaneada, inclusive, pelo Brasil como mostram os últimos acordos firmados por este. Em segundo lugar, em razão da própria evolução do direito internacional, mostrando, principalmente uma maior preocupação com temas importantes, tais como a responsabilidade social dos investidores, recorrente nos últimos IIAs firmados. 


\section{A evolução no conteúdo dos acordos de proteção de investimentos estrangeiros analisados}

No grupo de comparações $\mathbf{0 1}$ foram analisados 06 acordos, todos cujo Brasil figurou como entidade participante: Angola - Brazil BIT (2015); Brazil - Chile BIT (1994); Brazil - Chile BIT (2015); Brazil - France BIT (1995); Brazil - Portugal BIT (1994); e Brazil - Venezuela, Bolivarian Republic of BIT (1995).

Percebeu-se que os BITs mais novos (2015) possuem previsão de cláusula de responsabilidade social (CRS), em alguns casos com maior detalhamento. A cláusula da nação mais favorecida parece ser comportamento (NMF) padrão também dos acordos pesquisados.

Fato inusitado é que a previsão de proteção dos investimentos (PSI) foi observada com países mais influentes (França e Portugual), enquanto que não foi prevista no BIT com a Angola (2015).

Ainda, percebeu-se sempre menção a desapropriação ou expropriação direta e, em alguns casos a indireta (França, Portugal e Venezuela).

No grupo de comparações $\mathbf{0 2}$ foram analisados 4 BITs firmados pela Colômbia. Apesar do distanciamento temporal dos Acordos sob análise (de 1994 a 2017), foi possível identificar uma uniformidade, em especial quanto à previsão da cláusula da nação mais favorecida (NMF) e de cláusula com abordagem sobre expropriação e indenização (DES).

Ademais, cumpre ressaltar que os acordos mais recentes, firmados entre 2013 a 2017 passaram a prever medidas relacionadas ao meio ambiente, saúde, os direitos laborais e a responsabilidade social corporativa (CRS), denotando uma verdadeira tendência dos novos acordos de investimentos. O acordo firmado entre o Governo da Colômbia e o Governo da França (de 2014), por exemplo, revelou-se moderno e atento à importância de práticas responsáveis de direitos humanos, como standars a serem incorporados em suas políticas internas

No grupo de comparações $\mathbf{0 3}$ foram analisados acordos firmados pelo Chile, com uma variação temporal de 20 (vinte) anos (entre 1997 a 2017), o que permitiu observar eventual evolução nos tratados assinados pelo Chile, de sorte a facilitar a incorporação de cláu- sulas mais modernas e/ou exclusão de cláusulas menos favoráveis ao país hospedeiro.

Percebeu-se, claramente, uma evolução no que tange à incorporação de cláusulas guarda-chuva (CGC) e de responsabilidade social (CRS), ainda que não de forma tão detalhada como seria esperado. A crescente preocupação em compartilhar responsabilidades com o investidor parece seguir o mesmo caminho da preocupação em responsabilizar o país hospedeiro em caso de descumprimento do BIT.

O maior detalhamento da cláusula de tratamento justo e equitativo (TJE) no BIT firmado em 2016 (com Hong Kong) denota uma evolução na preocupação dos países signatários em eliminar ambiguidades da redação de seus tratados e delimitar exatamente até onde estão se comprometendo perante os investidores. Corrobora essa conclusão o fato de esse último tratado ter eliminado a cláusula da nação mais favorecida (NMF) que, como discutido em sala de aula, acaba por engessar as possibilidades de o país hospedeiro aproveitar o seu poder de barganha frente a outros países.

No grupo de comparações 04 foram analisados BITs firmados pela Comunidade Andina (hoje composta por Bolívia, Colômbia, Equador e Peru). Os dois acordos firmados pela Comunidade Andina com o Canadá (1998) e com a Comunidade Europeia (2003), por se tratarem de acordos gerais de comércio e investimentos e especialmente pela distância temporal, 1998 e 2003, não se verificou nenhum dos dispositivos que estavam sendo mapeados. Já o CPTPP, parece ser um acordo mais ajustados às demandas atuais, até mesmo em resposta a diversas demandas arbitrais observadas nas últimas décadas. Assim, o CPTPP traz previsão expressa sobre tratamento em caso de conflito armado, além do capítulo comumente observado no caso de expropriações. Traz, também, dispositivo que trata não só da responsabilidade social de forma genérica (artigo 9.17), mas também especificamente de questões relativas ao meio ambiente e saúde (artigo 9.16), o que, mais uma vez demonstra uma nova preocupação dos Estado quando da assinatura de acordos de investimentos.

No grupo de comparações $\mathbf{0 5}$, foram analisados dois BITs firmados pelo Uruguai, um de 2008 com a India e outro de 2015 com o Japão. Neste caso, notou-se a maior evolução em termos dos dispositivos mapeados, pois o primeiro acordo somente possuía metade dos itens (TJE, PSI e NMF). Já o acordo de 2015 segue a 
mais moderna tendência de incorporar as demais cláusulas, ainda que de forma parcial (CGC e CRS).

O grupo de comparações 06 analisou dois BITs firmados pela Venezuela, o primeiro datado de 1990 com a Itália e o outro de 2008 com o Vietnam, não sendo possível perceber nenhuma modificação significativa, pois a única alteração constatada foi a inclusão da cláusual de proteção e segurança dos investimentos, que não representa nenhuma evolução relevante nos BITs.

No grupo de comparações 07 foram analisados outros dois tratados latino-americanos, um assinado pela Bolívia (2002) e outro pela Argentina (1999) e são claros exemplos de acordos firmados por países dessa região na ocasião. O acordo de 1999 da Argentina é, na verdade, uma amostra dos BITs firmados pelo referido país, uma vez que a maioria de seus acordos de investimentos foi firmado na década de 1990 (dos 55 acordos em força atualmente, 43 foram assinados entre 1992 a 1999). E da análise observa-se a padronização dos acordos, tema muito debatido em sala de aula. Denota-se que foram acordos pouco discutidos entre seus representantes, estabelecendo cláusulas padrão que, muitas vezes, se mostraram insuficientes para proteção dos investimentos.

No grupo de comparações 08 a análise se deu sobre tratados firmados por países da América Central com um lapso temporal relativamente grande (1982 a 2018), o que permite ver uma clara evolução nos acordos. Exceto o acordo firmado entre Costa Rica e Reino Unido, o mais antigo de todos desse grupo, de 1982, todos os outros possuem a previsão do tratamento justo e equitativo. Quanto à proteção e segurança dos investimentos, a integralidade dos acordos faz essa previsão, mostrando-se uma cláusula praticamente unâni- me quando se trata de direito dos investimentos. Assim como a normativa relativa a desapropriações e cláusula da nação mais favorecida (exceto o BIT entre Guiana e Suíça, que não faz esse tratamento). Mas, de fato, a diferença mais gritante é percebida com relação à responsabilidade social, prevista somente nos acordos firmados pelo CACM (Central American Common Market). Os demais BITs não trazem essa questão.

Finalmente, no grupo de comparações 09, foram trazidos os acordos firmados pelo Mercosul e, ao que parece, por serem tratados envolvendo uma entidade ainda não tão organizada como a União européia, seus acordos carecem de maiores detalhamentos e especificidades, recaindo na mesma problemática da padronização. O Investment Facilitation Protocol, de 2017, aparece, assim, numa esteira mais moderna de elaboração dos acordos, prevendo clausula de responsabilidade social, por exemplo, o que, mais uma vez, demonstra a tendência dos novos BITs.

\section{Referências}

MINISTÉRIO DA INDÚSTRIA, COMÉRCIO EXTERIOR E SERVIÇOS (MDIC). Negociações Internacionais de Investimentos. Disponível em: $<\quad$ https://www.mdic.gov.br/comercio-exterior/negociacoes-internacionais/218-negociacoes-internacionais-de-investimentos/1949-nii-acfi>. Acesso em maio/2018.

FERNANDES, Érica Capella. FIORATI, Jete Jane. Os ACFIs e os BITs assinados pelo Brasil. RIL Brasília a. 52 n. 208 out./dez. 2015 p. 247-276. 
Para publicar na Revista de Direito Internacional, acesse o endereço eletrônico www.rdi.uniceub.br ou www.brazilianjournal.org.

Observe as normas de publicação, para facilitar e agilizar o trabalho de edição. 